\title{
A FORMAÇÃO NO DEBATE COMUNICATIVO DE JÜRGEN HABERMAS
}

THE FORMATION IN COMMUNICATIVE DISCUSSION OF JÜRGEN HABERMAS A FORMACIÓN EN EL DEBATE COMUNICATIVO DE JÜRGEN HABERMAS

\author{
Elaine Conte \\ Professora Doutora do Programa de Pós-Graduação em Educação no Centro Universitário La Salle. \\ elaineconte@yahoo.com.br
}

\begin{abstract}
RESUMO: O ensaio busca compreender os sentidos do conceito de formação na perspectiva comunicativa de Jürgen Habermas e averiguar de que modo a proposta pode contribuir na disposição para a formação discursiva de aprendizagens sociais, como uma atitude reconstrutiva que possibilita impulsos transformadores da vida em sociedade. Trata-se de enriquecer não só a investigação sobre a educação, mas também, entender as implicações, desdobramentos e possibilidades desse tipo de análise linguístico-pragmática no processo de formação humana. Repensar a formação no reconhecimento do outro que encarna um saber é fundamental à reelaboração dos processos de ensino canonizados, unilateralizadores e engessados institucionalmente, criando estímulos à atitude performativa e à democratização dos bens culturais, como algo sensível e coexistente à lógica do aprender cooperativo e à renovação da ação na conversação com as diferenças no mundo.
\end{abstract}

PALAVRAS-CHAVE: Formação discursiva. Aprendizagens sociais. Reconstrução comunicativa.

ABSTRACT: This essay seeks to understand the meanings of the concept of training in the communicative perspective of Jürgen Habermas and to find out how the proposal contributes to the provision for the discursive formation of social learning, as a reconstructive attitude that enables impulse transformers of society. It is not only enrich the research on education, but also understand the implications, consequences and possibilities of this kind of linguistic and pragmatic analysis in the process of human development. Rethinking education in recognition of the other that embodies a knowledge is essential to restate the canonized teaching processes, those who act unilaterally and plastered institutionally, creating incentives for performance attitude and democratization of cultural property, as something sensitive and coexistent to the logic of cooperative learning and renewal of the action in the conversation with the differences in the world.

KEYWORDS: Discursive formation. Social learning. Communicative reconstruction.

RESUMEN: El texto discute la posibilidad de favoritismo a la positividad de la enseñanza y el aprendizaje de la sociología, eEl ensayo busca comprender los sentidos del concepto de formación en perspectiva comunicativa de Jürgen Habermas y averiguar cómo la propuesta puede contribuir a la provisión para la formación discursiva de aprendizaje social, como una actitud reconstructiva que permite los impulsos transformadores de la sociedad. No sólo es enriquecer la investigación sobre la educación, sino también comprender las implicaciones, consecuencias y posibilidades de este tipo de análisis lingüístico y pragmático en el proceso de desarrollo humano. Repensar la formación en el reconocimiento del otro que encarna un conocimiento es esencial para reformular los procesos de enseñanza canonizados, unilateralizadores y endurecidos institucionalmente, con creación de incentivos para la actitud performativa y la democratización de los bienes culturales, como algo sensible y coexistente con la lógica del aprendizaje cooperativo y la renovación de la acción en la conversación con las diferencias en el mundo.

PALABRAS CLAVE: Formación discursiva. Aprendizaje social. Reconstrucción comunicativa.

Artigo recebido em setembro de 2016

Aprovado em novembro de 2016 


\section{A FORMAÇÃO NO DEBATE COMUNICATIVO | Elaine Conte}

\section{1| INTRODUÇÃO}

Falar de formação, hoje, na perspectiva de um pensador como Jürgen Habermas ${ }^{1}$ é apaixonante e controverso (pela multiplicidade de vozes dissonantes), visto que revitaliza a força propedêutica dos processos de aprendizagem e desperta entre os interlocutores a consciência de falibilidade de nossas interpretações. O agir comunicativo tem a ver com o reconhecimento intersubjetivo e a possibilidade de um sujeito se posicionar linguistica e criticamente quanto a pretensões de outro interlocutor, desenvolvendo assim, a própria formação e a comunicação democrática.

A educação no seu sentido mais amplo de processo de formação social, cultural e científico, pode ser considerada uma temática recorrente em Habermas, possuindo uma natureza descentralizada, crítica, comunicativa e de práxis argumentativa. Essa perspectiva, força os sujeitos capazes de falar e agir a uma contínua renovação e reinterpretação dos discursos, certezas, questionamentos e pesquisas, como possibilidade de contribuição reconstrutiva que os atores sociais prestam a partir de seu mundo e da vida². Para situar a complexidade do problema da formação, aproximamos ao campo da educação a linguagem de caráter formador de mundo na práxis social, que é o lugar onde a racionalidade pode ser mediada concretamente pelo outro, em termos de entendimento, consenso e seu uso pragmático (performance). Afinal, o que nos caracteriza como humanos são as diferenças e não as similaridades. Tais diferenças aparecem em diversos contextos da sociedade; como um jogo de linguagem; por isso a vontade de submeter a formação atual a uma análise habermasiana cujo intuito é fomentar reflexões críticas sobre a práxis comunicativa humana, em tempos de domínio das tecnologias.

Procuramos, assim, articular os conceitos habermasianos de linguagem, saber, racionalidade, ontologia e intersubjetividade com as singularidades da práxis humana, de modo a justificar a necessidade de recuperar a ideia de formação em sua força histórica e de equacioná-la na racionalidade do saber contingente e pluralista de mundos. Para proceder a essa investida, a hermenêutica filosófica ${ }^{3}$ torna-se um élan crítico, pois esclarece que só permanecem vivas as tradições que se modificam a si mesmas e em situações diferentes, pela reflexividade e pelos esforços interpretativos diários, que mantém a intersubjetividade aberta na conversação. Afinal, como Habermas assevera, pode-se dizer que o desenvolvimento da racionalidade deve contemplar os aspectos técnico-científicos, normativos e expressivos.

\footnotetext{
1 Jürgen Habermas (nascido em 1929) é um dos pensadores mais atuantes da atualidade. Estudou Filosofia, História, Psicologia, Economia e Literatura alemã e ocupa uma posição de crítico que não se furta às discussões da ágora virtual, abordando questões que tratam dos fundamentalismos e da tolerância religiosa, dos limites entre fé e ciência e das diversas formas de discurso. Pensador apreciado mundialmente desenvolve a virada pragmáticoreconstrutiva de intersubjetividade que dispensa a certeza absoluta e concebe a ação humana coordenada pela capacidade humana de falar e de agir, em uma compreensão descentrada (nós, equivalente à alteridade, que significa constituir-se como outro) do mundo.

2 "O mundo da vida intersubjetivamente compartilhado é, antes, definitivamente o lugar de uma práxis cotidiana cooperativa e comunicativa, na qual se sobressaem - como em Piaget - os traços inovadores-experimentais e os aspectos discursivos de processos de aprendizado falíveis, ou - como no último Wittgenstein - os traços interativos dos jogos de linguagem" (HABERMAS, 2004, p. 166).

${ }^{3}$ A atitude hermenêutica é, antes de tudo, palavra. Gadamer (1999) é o primeiro a acentuar a abertura ao diálogo como algo vivo, de experiência presente, na virtualidade da linguagem. Fazendo uma analogia com a educação, a ação pedagógica enquanto hipertextualidade da linguagem está enraizada no devir das realidades inapreensíveis, na ação e na sensibilidade para o acontecimento que se apresenta. Gadamer diz que não haveria orador nem arte da fala se as relações humanas não fossem sustentadas pela compreensão de um diálogo perturbado e pela busca de acordo.
} 


\section{A FORMAÇÃO NO DEBATE COMUNICATIVO | Elaine Conte}

É possível afirmar inicialmente que o endereçamento da formação no sentido da socialização da cultura ${ }^{4}$ evita recair no extremo de formar unilateralmente para apenas uma das dimensões da racionalidade, pois envolve a dimensão do outro, do coletivo, das diferenças, contrariando o estigma do professor enclausurado em fórmulas abstratas e de difícil acesso para o grande público. De modo especial, Habermas desenvolve um conceito de racionalidade no enraizamento do saber humano na prática social, para dar conta da totalidade humana, e nos ajuda a detectar certas patologias ocorridas ao longo do processo de modernização, que causaram o encolhimento da racionalidade comunicativa frente aos avanços da razão instrumental e que podem ter na educação tanto o ambiente de disseminação quanto de controle. Discutindo os pressupostos performativos da linguagem, atinge-se a valorização da vida e das experiências cotidianas, tornando o conhecimento sensível ao sujeito e à própria democracia. Considerando o caráter interativo do processo pedagógico, o tema da formação interpela os limites de pressupostos teóricos que escapam aos padrões idealizados do processo constitutivo da sociedade, que passa a ser integrada no ato crítico, discursivo e autorreflexivo do sujeito.

A relevância do estudo está em estimular a busca de novos caminhos intersubjetivos e de estudo acerca do conceito de formação, que se apresenta como uma discussão aberta e que pode trazer novos sentidos ao saber, poder, (re)conhecer e à cultura contemporânea. Vale ressaltar que o processo de elaboração desta pesquisa procurou compreender o seguinte movimento: primeiro, buscamos esclarecer conceitualmente os sentidos de formação no entendimento habermasiano; segundo, objetivamos recolocar os sujeitos agentes (autônomos), na dimensão performativa como território legítimo à própria percepção da vida, retomando os problemas que permaneciam suspensos pela função representativa da linguagem na educação; terceiro, procuramos resgatar e sistematizar as principais ideias de Habermas sobre a formação, tendo como princípio o processo social, comunicativo, público e inesgotável, apoiado no entrecruzamento complementar do acesso ao mundo pela ação impessoal e pelo despertar performativo, pois os modos de agir dependem exclusivamente de nós em relação ao outro e da realidade social complexa, que é uma forma de vida.

\section{2 | ESCLARECIMENTOS CONCEITUAIS E SENTIDOS DA FORMAÇÃO EM HABERMAS}

Habermas (1987a) defende o conceito de ação comunicativa como princípio de socialização e reflexão, mediante um saber holístico sustentado na totalidade, globalidade, contextualizado no imaginário, na utopia e na imaginação, como fatores instituintes das relações sociais, de uma escrita de muitos dizeres, que sacode nossas certezas de sentido do mundo. Habermas (2004) alicerça o fundamento epistemológico da formação na circularidade entre ação e discurso na práxis do encontro com os problemas da cotidianidade, visto como possibilidade de níveis de aprendizagem sempre mais elevados, como revisão e confronto do saber com o mundo da vida. "Mas a racionalidade comunicativa corporificada em atos ilocucionários também se estende, para

\footnotetext{
${ }^{4}$ Denominamos cultura (Paideía, Bildung, Lumiéres) ao que se poderia chamar de uma dimensão formadora dos conhecimentos e das formas de vida, isto é, "o arsenal de saber no qual os agentes comunicacionais, ao entenderem-se mutuamente sobre algo que está no mundo, se munem com interpretações potencialmente consensuais" (HABERMAS, 1987a, p. 209). Para Cambi (1999, p. 87), a compreensão da historicidade da formação "porá em circulação aquela noção de paideía que sustentou por milênios a reflexão educativa, reelaborando-se como paideía cristã, como paideía humanística e só depois como Bildung". [a transliteração do termo paideía foi corrigida, conforme as normas da Sociedade Brasileira de Estudos Clássicos]. Nesse horizonte, formação e educação coincidem, ainda que, na totalidade, uma não possa reduzir-se a outra.
} 


\section{A FORMAÇÃO NO DEBATE COMUNICATIVO | Elaine Conte}

além de proferimentos verbais, a ações ou interações sociais" (HABERMAS, 2004, p. 117). Desse ponto de vista, identifica na interação entre a abertura linguística ao mundo e os processos intramundanos de aprendizado, por natureza complexos, a possibilidade de convergência entre teoria, pesquisa e práxis ética formadora da vontade.

Diante das limitações comunicativas e das experiências práticas mal sucedidas no mundo, os discursos surgem como renovação das práticas ingênuas e revalidação dos saberes no respectivo contexto de justificação. Daí advém a força do discurso que equaciona as verdades tornadas problemáticas no contexto vital, para que elas possam ser reintegradas na ação performativa, uma vez que só a linguagem pode ser o vínculo intersubjetivo pelo qual esses significados ganham corpo (HABERMAS, 2004). Segundo Habermas (2004, p. 52), "[...] na medida em que o saber se justifica por um processo de aprendizado que supera os velhos erros mas não nos protege dos novos, cada estado de saber atual permanece relativo à melhor situação epistêmica possível". É no discurso que adotamos uma atitude de entendimento como possibilidade de coordenação das ações e orientação motivadora da formação da vontade, por meio da cooperação entre perspectivas interpretativas. Esse vínculo com o discurso para deliberar sobre os problemas da prática garante um processo de aprendizagem formativa que aposta na própria experiência em um mundo mais amplo de relações interpessoais legítimas. Assim,

O conceito de racionalidade comunicativa remete, por um lado, às diversas formas de desempenho discursivo de pretensões de validez (por isso Wellmer fala também de racionalidade discursiva); e por outro lado, às relações que em sua ação comunicativa os participantes estabelecem com o mundo ao reclamar validez para suas manifestações ou emissões; daí que a descentração da visão de mundo tenha se revelado como a dimensão mais importante da evolução das imagens do mundo. (HABERMAS, 1987a, p. 111).

A ideia de desenvolver um processo de formação sempre mais avançado mostra o papel reflexivo da comunicação para a autonomia pública ${ }^{5}$, no sentido de colocar-se no lugar do outro e da renovação constante dos saberes. A força ilocucionária assegura o diálogo entre diferentes mundos, pois "com a força ilocucionária de uma emissão pode um falante motivar um ouvinte a aceitar a oferta que penetra seu ato de fala e com isso a contrair um vínculo (Bildung) racionalmente motivado" (HABERMAS, 1987a, p. 358). O professor como um ator social não pode obter uma verdadeira autorreflexão necessária à dissolução crítica de autoilusões (que não significa um progresso do saber, mas uma perda de ingenuidade) ou a descentração das perspectivas de cada sujeito, sem se dar conta do caráter social do processo formativo.

As possibilidades de uma reconstrução comunicativa, no sentido de trabalhar em um plano diferente determinados conceitos, reforçam um discurso de cidadania, através do questionamento dos saberes isolados, de racionalização neutra, o que se expressa na possibilidade do processo formativo estar inserido no mundo da vida, na medida em que se volta para a formação discursiva da vontade, através de leitura de imagens e conteúdos, que se sustentam a partir da necessidade de uma educação ética e estética para a vivência do espaço público.

\footnotetext{
${ }^{5}$ Habermas retoma o sentido de opinião pública para designar o que se falava até então de "mundo dos leitores", de "todo o mundo" ou também simplesmente de "mundo", mas em ambos os casos, trata-se de um "público que julga", um modo de ver da multidão, que é questionável no cerne (HABERMAS, 1984, p. 40-41). Habermas propõe três tipos de esfera pública. A esfera pública episódica (bares, cafés, encontros na rua); a esfera pública de presença organizada (encontro de pais, público que frequenta o teatro, concertos de Rock, reuniões de partido ou congressos de igrejas) e a esfera pública abstrata, produzida pela mídia (leitores, ouvintes e espectadores singulares e espalhados globalmente).
} 


\section{A FORMAÇÃO NO DEBATE COMUNICATIVO | Elaine Conte}

A partir da análise sobre a formação, chega-se à Bildung, que se define como uma palavra surgida no final do século XVIII, imbuída de filosofia, estética, pedagogia e ideologia. É um projeto de entendimento que visa pôr em atividade todas as forças do ser humano para desenvolver-se, significando ao mesmo tempo educação, formação humanística de valores e o comportamento pelo qual conduzimos nosso caminho nas relações sociais. Trata-se de um processo autoformativo da humanidade "vinculado às ideias de ensino, aprendizagem e competência pessoal", de formar e formar-se, de educar e educar-se, adquirindo uma cultura no diálogo autêntico com a realidade e no entendimento do ponto de vista do outro (GADAMER, 1991, p. 38). A formação é considerada um sistema de forças que permanece em constante tensão e conflito, presumindo uma compreensão dialética do universo cultural, pois a humanidade em toda a sua complexidade aspira chegar à maioridade (Mündigkeit) $)^{6}$. Nesse sentido, a situação aludida remete ao diálogo socrático e à formulação baseada na tradição kantiana do uso público da razão, cujo objetivo da educação estaria na vontade de emancipação associada à autonomia da voz ativa, que concebe o sujeito esclarecido como resultado de uma interação crítica e linguística com a realidade social (MAAR, 1994).

De acordo com Habermas, a força ilocucionária do ato de fala, isto é, a intenção de fala voltada para a busca do melhor argumento, guarda pretensões de veracidade que só podem se manifestar como um compromisso no uso público da racionalidade. A emancipação "tem a ver com a libertação em relação a parcialidades [...]. A emancipação é um tipo especial de auto-experiência porque nela os processos de auto-entendimento se entrecruzam com um ganho de autonomia" (HABERMAS, 1989b, p. 99). Mas, quais as possibilidades de articular o potencial reflexivo e imaginativo do discurso no mundo de hoje? Até que ponto a ciência e a técnica separadas do mundo da vida podem produzir desvios e o enrijecimento do processo formativo? Como desenvolver um diálogo formativo na atualidade? As questões acima são centrais para a formação, justamente porque projetam a questão da relação intersubjetiva com o outro, a diversidade, a diferença, a coordenação da ação e a capacidade de decidir, considerando os espaços sociais de aprendizagens e de disputa pelos sentidos da ação pedagógica. Na educação, a linguagem denunciada por Habermas (1996) ainda se desenvolve de forma auxiliar, com fins didáticos de imposição, de relações controladoras, ritmadas em explicações, tomando a linguagem instrumentalmente a serviço de uma pedagogização?.

Nessa perspectiva, uma das respostas a esses questionamentos tem sido que "a racionalidade comunicativa não se corporifica num processo de entendimento mútuo fundado sobre pretensões de validade senão quando falante e ouvinte se entendem (querem se entender) a respeito de algo no mundo numa atitude performativa - voltada para segundas pessoas" (HABERMAS, 2004, p. 112). Nas palavras de Trevisan (2002, p. 144), "a formação da vontade pública esclarecida é um argumento plausível no ambiente pedagógico, desde que percebamos o real alcance da dimensão dessa proposta em termos práticos de transformação social". Isto reflete que a vontade coletiva formada no sentido pleno é o alicerce do convívio democrático para viabilizar uma democracia participativa, formando comunidades de aprendizagens capazes de se comunicarem e

\footnotetext{
${ }^{5}$ Mündigkeit, literalmente maioridade, é um conceito da filosofia clássica alemã, merecendo destaque no texto Resposta à Pergunta: o que é esclarecimento? "Sapere Aude! Tem coragem de fazer uso de seu próprio entendimento, tal é o lema do esclarecimento" (KANT, 1996, p. 100). A Mündigkeit de um sujeito ou de um grupo é concebida como o telos de um processo evolutivo ou de um processo de formação, que torna o sujeito capaz de pensar por si mesmo, superando a acomodação quase natural.

${ }^{5}$ Pedagogização é reinterpretada aqui como a regulação e o operar técnico da palavra, que tutela os processos e tempos de formação, assim como os ritmos de aprendizagem, reduzindo-os ao esquema ensino-aprendizagem, transmissão-aquisição.
} 


\section{A FORMAÇÃO NO DEBATE COMUNICATIVO | Elaine Conte}

aprenderem colaborativamente. As aprendizagens sociais advêm da atuação performativa dos sujeitos no mundo, que permite uma abertura ao outro, sendo o móbil mais efetivo para as atividades de discussão, descoberta e criação, próprias da semântica da formação. Se todos os seres humanos no mundo se relacionam uns com os outros através da possibilidade ontológica da linguagem, então "a realidade com a qual confrontamos nossas proposições não é uma realidade nua, mas já, ela própria, impregnada pela linguagem. A experiência pela qual controlamos nossas suposições é linguisticamente estruturada e se encontra engastada nos contextos de ação" (HABERMAS, 2004, p. 45). A compreensão de Habermas amplia o debate para a educação em contextos pluralistas e globais, ao afirmar que:

Os processos de comunicação sofrem a influência dos meios de comunicação de massa, seja de modo direto, seja em maior escala através dos "líderes de opinião". Entre estes encontram-se com frequência aquelas pessoas dotadas de opiniões refletidas, formadas através de discussões literárias e racionais. Na medida, contudo, em que tais opiniões permanecem externas ao contexto comunicativo de um público intato, elas pertencem da mesma forma às opiniões não-públicas. (HABERMAS, 1971, p. 197, grifo do autor).

Tendo em vista essa circunstância, as instituições de ensino são herdeiras dessa forma de opinião massiva por não conseguirem, muitas vezes, traduzir os conhecimentos científicos para a dimensão do grande público, resultando na falta de raciocínio público, de iniciativa dos professores e na redução aos saberes técnicos e do caráter político aos modismos. A ausência de processos de entendimento sobre os discursos vigentes causa acomodação e uma ameaça à liberdade pedagógica, pois esta fica a mercê dos imperativos sistêmicos, que mostram os limites e condicionam nossos modos de ver, sentir e agir comunicativamente. Habermas (1987a) estabelece um conceito de racionalidade comunicativa capaz de fazer frente às reduções cognitivo-instrumentais, levando em consideração questões simples da vida cotidiana, que se realizam entre os envolvidos no processo de conversação. Assim, revela uma preocupação com as redes de comunicação que avançam como uma racionalidade sistêmica na produção de imagens, transformando o conhecimento e a arte em mercadoria. Na atualidade, os próprios conteúdos culturais encontram-se virtualizados nas redes de informações, sendo que a ciência e a técnica, transformadas pelas tecnologias virtuais, modificam o mundo do trabalho em atividades cada vez mais abstratas, concentradas em serviços, que transformam o conceito de mera produção no binômio trabalho e interação (MARTINI, 2007). A cultura que vive nessa forma de comunicação parece não exigir mais a necessidade de um processo de formação mediado dialogicamente pelo professor.

Em contrapartida, a ação performativa emerge como realização intersubjetiva e elemento mediador do entendimento e da integração social no horizonte do mundo da vida, alcançando um movimento de expressão na reviravolta linguístico-pragmática. Esse giro linguístico é poroso porque corrói certezas obtendo, através da linguagem, o consenso que não apaga, no momento do acordo, as diferenças das perspectivas dos falantes, uma vez que somos sujeitos sempre suscetíveis a novas compreensões do outro e de nós mesmos. Desta maneira, a autoconsciência possui um núcleo intersubjetivo que testemunha a dependência contínua da subjetividade face à linguagem, que é o meio através do qual alguém se reconhece no outro de modo não-objetivado. Neste ponto, surge a controvérsia e a discussão que é a origem da formação da opinião, pois,

[...] um método de controvérsia pública que se impusesse de tal maneira teria por efeito afrouxar as formas repressivas de um consenso produzido sob pressão tanto quanto o de amenizar os conflitos até agora subtraídos à esfera pública. O conflito e o consenso, tal como a própria dominação e o poder, cujos graus de estabilidade elas definem analiticamente, não são categorias pelas quais o desenvolvimento histórico da sociedade passe sem deixar vestígios. (HABERMAS, 1971, p. 200). 


\section{A FORMAÇÃO NO DEBATE COMUNICATIVO | Elaine Conte}

A controvérsia deve ser vista como constitutiva das diferenças humanas, e por isso, preserva o caráter formador e dialético de uma sociedade mais evoluída. Sob essa ótica, através da mudança estrutural da esfera pública pode-se estudar algumas saídas para que a formação pedagógica não permaneça refém dos discursos transmitidos pelos meios de dominação, que legitimam uma prática apassivada e limitada de conversação pública. Conforme acentua Gadotti (1985, p. 125), "na prática de ensino existe também o conflito, que não anula o diálogo, que é parte dele". O papel do educador é desvelar contradições e antagonismos, organizar a resistência e o conflito, o que leva a reivindicar nos cursos de Pedagogia mais espaço para o diálogo, a expressividade e a esfera corporal, que revela todo o impulso sensível e todo o ser enquanto manifestação da vontade que movimenta ações. A concepção da falibilidade dos saberes mostra a necessidade de se estabelecer constantemente novos processos de entendimento, o que só é possível através da argumentação racional, ou seja, pela reflexibilidade. Afinal,

[...] as estruturas de racionalidade não se materializam apenas nos mecanismos do agir racional com relação ao fim - e, portanto, em tecnologias, estratégias, organizações e qualificações -, mas também nas mediações do agir comunicativo, nos mecanismos que regulam os conflitos, nas imagens de mundo, nas formações de identidade. (HABERMAS, 1990a, p. 34-35).

O mais curioso é que a maior parte da humanidade e, diga-se de passagem, grande parcela dos professores, vive instantes de limitadas perspectivas, de carência teórica, de desvalorização profissional, de imobilidade prática e de falta de base racional em relação ao futuro. Paradoxalmente, expande-se a literatura futurista, imaginativa, ilusória e vicejam, naquelas instâncias em que as ciências positivas não opinam, as explicações pseudocientíficas e os conhecimentos triviais, acomodando os professores e banindo uma necessária reflexão crítico-emancipatória. Esse tema interpela os que consideram a vulnerabilidade das crianças e dos jovens diante dos apelos midiáticos, cabendo ao professor um trabalho que favoreça a postura crítica para ler e interpretar as mensagens.

Segundo Martín-Barbero (1996, p. 19), o desafio cultural está na inserção crítica dos meios de comunicação e das tecnologias, pois "não só descentram as formas de transmissão e circulação do saber como também constituem um decisivo âmbito de socialização através dos mecanismos de identificação/projeção de estilos de vida, comportamentos, padrões de gosto". As linguagens dos artefatos tecnológicos são bloqueadas de sentido e pensamento na educação porque, muitas vezes, não estabelecem formas de diálogo com a realidade, dispensando o sujeito de exercer a própria cidadania. É necessário o reconhecimento, por parte do professor, da existência de diferentes maneiras para trabalhar com o conhecimento, não apenas como reprodução cultural, mas como algo socialmente construído e em construção intersubjetiva, afinal, o diálogo ainda é uma instância que os meios tecnológicos não conseguem compreender satisfatoriamente. Segundo o ponto de vista habermasiano, a linguagem é concebida como garantia da democracia, isto é, uma forma política derivada de um livre processo comunicativo voltado a conseguir acordos consensuais em decisões coletivas. Para o autor,

sob o aspecto funcional do entendimento, a ação comunicativa serve à tradição e à renovação do saber cultural; sob o aspecto da coordenação da ação, serve à integração social e à criação da solidariedade; sob o aspecto da socialização, finalmente, serve à formação das identidades culturais. (HABERMAS, 1987b, p. 196).

Vale dizer que a efetividade do agir comunicativo perpassa pelo reconhecimento de um mundo comum, que abrange o mundo objetivo (possíveis enunciados verdadeiros), o mundo social 


\section{A FORMAÇÃO NO DEBATE COMUNICATIVO | Elaine Conte}

(relações sociais legitimadas) e o mundo subjetivo (vivências individuais), o que torna o agir comunicativo o princípio da compreensão mútua do mundo da vida. Por isso, Habermas fala em consenso ${ }^{8}$ pragmático. A práxis comunicativa é condição para a mediação e formação da cultura.

Nesse viés, a inserção de processos de entendimento extrai uma racionalidade diretamente implicada no processo de vida social, pois o tecido das ações comunicativas alimenta-se de recursos do mundo da vida e é, ao mesmo tempo, o meio através do qual se reproduzem as formas de vida concretas. A educação que valoriza a multiplicidade de dizeres caracteriza-se pela negação de fazer a educação sem o outro, isto é, não se trata simplesmente de transmitir conhecimentos teóricos, antes, trata-se de extrair da realidade novas formas de conhecer e interpretar o mundo, a partir de correlações e interrelações comunicativas. Torna-se assim, "possível a forma de consenso sem coações e o tipo de intersubjetividade flexível, do que depende a ação comunicativa" (HABERMAS, 1994, p. 222), pois, o saber reflexivo impõe-se todas as vezes que se pretende reconstituir a unidade quebrada, fragmentada do homem, para que esse possa tomar consciência de si mesmo como um ser que tem uma identidade pessoal, bem como uma tarefa de existir e agir na presença dos outros.

A comunicação, essencialmente interativa e não mais embasada exclusivamente na relação meio-fim (ação tecnológica), viabiliza uma complementaridade e um intercâmbio fluente entre os universos teórico e prático, uma conduta que preconiza a ação informada, orientando as questões do cotidiano e colaborando para a qualificação educativa. Habermas (1987a) defende um conceito de racionalidade que se projeta em duas vias, por um lado, a racionalidade cognitivo-instrumental, que tem a conotação de uma autoafirmação voltada para o êxito no mundo objetivo, pela capacidade de manipulação instrumental e, por outro, a racionalidade comunicativa, que objetiva o entendimento comunicativo com base na argumentação em que os participantes superam a subjetividade inicial de seus pontos de vista e se asseguram de uma unidade do mundo objetivo e da intersubjetividade do contexto em que desenvolvem suas vidas. Assim, define a complexidade da formação como sendo o conjunto edificado de saber no qual os agentes comunicacionais, ao entenderem-se sobre algo que está no mundo, se munem com interpretações potencialmente consensuais. Para o autor, nos processos comunicativos de formação se constituem e mantém conjuntamente a identidade do sujeito e do coletivo com o próprio mundo da vida, da cultura e da linguagem.

A racionalidade comunicativa, voltada ao entendimento e fortalecida via educação, pode ser o caminho para reverter o cenário de competitividade, de egoísmo e de ausência de solidariedade que caracteriza o mundo de hoje. Seu caráter dialético é, ao mesmo tempo, espaço de infiltração da racionalidade sistêmica e de reabilitação da racionalidade comunicativa. Contudo, torna-se necessário que o professor tenha uma postura de resistência e de crítica frente à formação cultural tradicional, para incentivar no seu público a capacidade de decodificar a manipulação ideológica, unindo esforços para que a discussão coletiva possa ser potencializada na educação. O professor que desenvolve os meios argumentativos através dos quais se pode obter um entendimento intersubjetivo (compreensão mútua) acerca da pretensão de validade está mediatizando o processo

\footnotetext{
${ }^{8} \mathrm{O}$ consenso em Habermas surge como possibilidade de reencontrar a racionalidade esclarecedora, e associa-se a uma discussão responsável mediada por normas, que racionalmente garantem o valor das atividades linguísticas, o que permite a coordenação das ações e a socialização da cultura sem repressão. A garantia da existência humana depende da manutenção do acordo comunicativo, graças ao qual os sujeitos alcançam o entendimento, unindo-se pela validade alcançada no interior do reconhecimento intersubjetivo, para a manutenção de acordos mínimos que possam socializar normas justas e assegurar a integridade vital. O consenso segue a lógica do melhor argumento em que "diversos participantes superam a subjetividade inicial dos seus respectivos pontos de vista e perante uma comunidade de convicções racionalmente motivada se asseguram por sua vez da unidade do mundo objetivo e da intersubjetividade do contexto em que desenvolvem suas vidas" (HABERMAS, 1987a, p. 27).
} 


\section{A FORMAÇÃO NO DEBATE COMUNICATIVO | Elaine Conte}

pelo qual uma opinião pode transformar-se em saber. "À consciência moderna do tempo devese também a definição de que a práxis está orientada para o futuro e produz o novo. Ao tomar a iniciativa, aquele que age transcende todas as determinações dadas e constrói um novo começo" (HABERMAS, 1990b, p. 457).

Nessa perspectiva, Martini (2006) sugere uma proposta de um currículo reconstrutivo de formação de professores, baseado em tarefas conceituais e práticas discursivas, centrado numa ação educativa interdisciplinar, desempenhada em diferentes espaços pedagógicos, num progressivo esforço de descentramento e apropriação reflexiva da prática educativa. É uma abordagem que verifica a necessidade de um currículo que articule os aspectos intelectuais e técnicos da formação (conteúdos e métodos) com a consideração de fatores de ordem política, dialógica, expressiva, afetiva, sensível e corporal do professor, enfim, que contemplem o ser humano como um todo.

A atitude pedagógica investida nos processos de comunicação situa-se justamente na criação de oportunidades para pensar as diferenças, o ambíguo, abrindo-se para o mundo vivido, cuja legitimidade das normas é garantida por processos de validação discursiva. Trata-se de um pensamento revolucionário porque permite que práticas e crenças cristalizadas ao longo dos tempos sejam reconstruídas nos cursos de formação de professores, o que implica em capacitá-los a questionar permanentemente rótulos, teorias e perspectivas subjacentes à ação docente.

Nesse panorama de discussão, Habermas (1989a, p. 197) acrescenta que "a competência interativa não se mede pela capacidade de solucionar problemas de conhecimento e morais, mas sim pela capacidade de manter processos de entendimento também em situações de conflito (por via da reflexão), ao invés de romper a comunicação ou mantê-la apenas em aparência". Nesse sentido, a racionalidade da ação educativa passa a ser compreendida como uma racionalidade de potencial expressivo e de acesso ao outro, articulada aos elementos estético-formativos, em contraposição a uma racionalidade puramente técnico-instrumental.

Tudo indica que o conhecimento nasce da ação no mundo e com o outro, sendo que este mundo precisa ser constantemente revisto e reinterpretado pelos sujeitos para que eles aprendam, não só adquirindo conhecimentos objetivos, mas aprendam a ouvir as tradições e a pensar criticamente a realidade com os outros (MARTINI, 2005). O que Habermas defende é que "o entendimento linguístico implica numa adesão pragmática e prática não só às regras discursivas, mas um compromisso prático-ético com os critérios do entendimento no sentido da busca cooperativa do que é verdadeiro, justo e belo" (MARTINI, 2007, p. 270).

Portanto, o diálogo e a crítica são elementos constitutivos da própria ação comunicativa e quando esta comunicação sofre bloqueios pode ocorrer a mera adesão acrítica a políticas econômicas, sociais e culturais, invadindo o mundo da vida e tornando-o intransparente enquanto discurso problematizador. Neste sentido, o agir educativo enquanto processo performativo da ação humana pode ser compreendido a partir do binômio mundo da vida, porque pode ser entendido como instrumento de passagem da tradição, reproduzindo a vida social e a personalidade, e sistema pelo fato de ser regido por leis e organizado burocraticamente. Parafraseando Austin (1911-1960), podemos dizer que o êxito da comunicação corresponde ao êxito da própria formação e da ação pedagógica, pois falar algo é recriar e ampliar as bases de ação no mundo. 


\section{A FORMAÇÃO NO DEBATE COMUNICATIVO | Elaine Conte}

\section{3 | A QUESTÃO PERFORMATIVA9 ${ }^{9}$ EM HABERMAS}

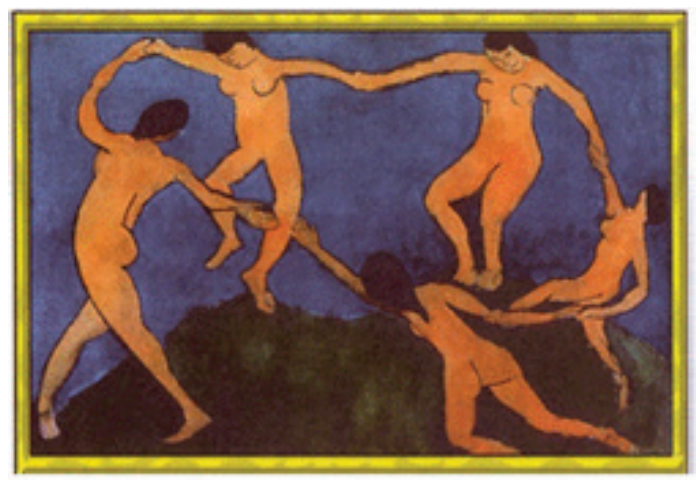

A Dança - Matisse 1978

A dança de Matisse ilustra o sentido integrador e mobilizador da vida em obra, que retoma aqui o imaginário de criação e o patamar performativo da linguagem, cuja expressão justifica seu sentido na intersubjetividade da ação, no fórum público de argumentação e na formação de aprendizagens sociais. Projetar o jogo da formação (ser em manifestação, em participação) no mover-se na dança humana retoma dimensões da liberdade do criar a si mesmo com o outro, sendo uma alternativa plausível para atualizar as performances pedagógicas. Como bem observa Gadamer (1999, p. 151, grifo do autor), "[...] todo o encontro com a linguagem da arte é o encontro com um acontecimento inacabado, sendo ela mesma parte desse acontecimento". As proposições de Gadamer sobre a obra de arte como jogo de linguagem remete à performance, pois provoca o encontro com o inacabado da experiência estética, em meio a processos intersubjetivos, que ampliam a autocompreensão e evidenciam a finitude humana (frente ao jogo com a obra, com o outro, consigo mesmo e com o mundo). A vida se efetiva na capacidade de julgamento, trazendo o instante criador e a capacidade de reconhecer e dizer o mundo, uma vez que nossa racionalidade é virtualmente linguagem. Mais especificamente,

A ocasionalidade do falar humano não é uma imperfeição eventual de sua capacidade expressiva. É, antes, a expressão lógica da virtualidade viva do falar que, sem poder dizêlo inteiramente, põe em jogo todo um conjunto de sentido. Todo o falar humano é finito no sentido de que abriga em si uma infinitude de sentido a ser desenvolvida e interpretada. (GADAMER, 1999, p. 591).

A linguagem apresenta, ao mesmo tempo, a experiência da finitude e da infinitude, em decorrência da fala estar em constante formação e desenvolvimento. Sendo assim, torna-se possível afirmar que, com a performance, "se introduz uma atitude realizativa (performative Einstellung) de tipo global, para dar conta de que com cada ato de fala os participantes da comunicação se referem simultaneamente a algo no mundo objetivo, no mundo social e no mundo subjetivo" (HABERMAS, 1987a, p. 422, grifo do autor). Para Habermas (1990a), o projeto normativo da modernidade precisa ser complementado por discursos sobre sua aplicação de forma a descentralizar a racionalidade, liberando as forças reprimidas do homem por meio da manifestação artística do vital e

\footnotetext{
${ }^{9} \mathrm{O}$ termo performance surge como um conceito correlato ao de racionalidade comunicativa, que é simultaneamente voz, gesto e corpo (pragmática, estética e expressiva). A ideia de uma racionalidade comunicativa remete, em primeiro lugar, às diversas formas de desempenho discursivo, na medida em que está ligada à ação do homem no mundo (HABERMAS, 1987a).
} 


\section{A FORMAÇÃO NO DEBATE COMUNICATIVO | Elaine Conte}

do originário. Isso se reflete no abandono do teor ético-moral e estético-expressivo da formação humana, que precisa ser explorado pela apreciação descentrada e sensível da realidade em interlocução pedagógica, se quisermos alcançar as formas de expressão adequadas às energias literárias das obras de nosso tempo. Habermas (1990a) explica a experiência estética como abertura para uma subjetividade descentrada, manifestada no relacionamento intersubjetivo e liberada das convenções e limitações da cognição, da atividade perlocucionária com respeito a fins, dos imperativos do trabalho e da mera utilidade. Trata-se de retomar o significado da experiência estética para a formação discursiva da vontade, como ação criadora de sentidos, capaz de afirmar a vida transitória, conflituosa, que não se ajusta aos limites da racionalidade, para reencontrar o sentido na ação pungente.

Habermas (1997) mantém vivas as esperanças e preocupações nos potenciais estéticos e revolucionários do conhecimento, pois vê uma descentração no processo de aprendizado (simpatia e afetiva pelo outro), que possibilita experienciar a relação com o mundo como algo significativo e prazeroso, desempenhado pela sensibilidade nos acontecimentos interativos. Nessa interpretação, a experiência estética passa a ser a linguagem capaz de assimilar socialmente o discurso emudecido das necessidades pessoais e culturais de modo a evitar uma emancipação infeliz ${ }^{10}$. $\mathrm{Na}$ verdade, "os processos de formação da opinião e da vontade, agregados a nível superior e condensados publicamente, mas próximos do mundo da vida, deixam transparecer um entrosamento estreito entre socialização e individuação, entre identidade do eu e identidade do grupo" (HABERMAS, 1990a, p. 343). A questão da performance é apresentada de forma mais enfática por Habermas sob a clarividência do uso comunicativo da linguagem, que agrega todos os produtos da cultura, da arte, da vida cotidiana, da literatura, do cinema, como elementos linguísticos para encontrarmos respostas às perplexidades do mundo e ao processo formativo.

$\mathrm{Na}$ verdade, o potencial das experiências estéticas, centrado no corpo, próprio a uma subjetividade descentrada desempenha a função de lugar do outro da racionalidade e amplia a disposição dos sujeitos capazes de falar e agir (HABERMAS, 1990a). A dimensão do corpo embora constituinte da totalidade da ação humana, como forma de percepção sensorial e linguística (de expressão que libera aspectos da emoção e da afetividade ${ }^{11}$ ), vem tradicionalmente sendo ignorada enquanto produção do discurso vivo ao projeto pedagógico. Talvez porque um dos limites humanos está na linguagem quando tenta abarcar a ação do corpo humano na dinâmica do trabalho conjunto (pois no trabalho pedagógico o estudante torna-se parceiro no saber pensar e no aprender indissociável do ensinar). Para sermos artífices ${ }^{12}$ inteligentes de nosso trabalho, sustentamos

\footnotetext{
${ }^{10}$ Habermas problematiza o risco da emancipação infeliz como hipótese à construção de uma ordem política do sujeito competente, porém infeliz em sua autorrealização, porque está desvinculada de uma preocupação com a felicidade humana. Kant (1996, p. 29), ao lastimar a situação política da segunda metade do século XVIII, assim se manifesta: "[...] nas condições atuais pode dizer-se que a felicidade dos Estados cresce na mesma medida que a infelicidade dos homens. E não se trata ainda de saber se seríamos mais felizes no estado de barbárie, onde não existiria toda essa nossa cultura, do que no atual estado. De fato, como poderíamos tornar os homens felizes, se não os tornamos morais e sábios?".

${ }^{11}$ Há uma tendência em psicologizar esta dimensão e repreendê-la como forma de garantir a cientificidade da educação. Mas esta vivência subjetiva não está descolada das circunstâncias histórico-sociais, pois o sujeito formase para o mundo integrando-se em um movimento que permeia a cultura, o contato e o convívio intersubjetivo, inserindo a tradição no seu mundo da vida. No que tange ao papel das emoções, dos sentimentos, dos desejos, da vontade, da decisão, da resistência, da escolha, da curiosidade, da criatividade, da intuição, da esteticidade, da boniteza da vida, do mundo e do conhecimento, Freire (2000) reafirma a amorosidade e a afetividade, como fatores necessários da vida humana e da educação.

${ }^{12} \mathrm{~A}$ palavra artífice evoca imediatamente um sujeito empenhado e dedicado à arte pela arte, cuja atividade tem caráter
} 


\section{A FORMAÇÃO NO DEBATE COMUNICATIVO | Elaine Conte}

a seguinte hipótese: "primeiro, que todas as habilidades, até mesmo as mais abstratas, têm início como práticas corporais; depois, que o entendimento técnico se desenvolve através da força da imaginação" (SENNETT, 2009, p. 20-21).

A experiência do professor parte do saber da tradição cultural em conjugação com a experiência presente, interdisciplinar, o que a torna fonte inesgotável e originária de acontecimento, sob a forma constitutiva do movimento da atuação e do pensamento sensível no processo coletivo. Vale notar que quando "se escolhe explicitamente a ação comunicativa como ponto de referência para a projeção utópica de uma sociedade racional, normas e valores se desestabilizam" (HABERMAS, 1987b, p.131). Com efeito, é nas suas formas linguísticas que o saber se constrói e, ao fazer-se, produz descentramentos de mundos, práticas coletivas e aprendizagens sociais concernentes ao lugar e tempo onde se fala (podemos citar como exemplo atual os Conselhos Escolares). $\mathrm{O}$ descentramento indica uma sensibilidade ampliada ao que permanece não assimilado (emudecido) nos resultados do domínio pragmático, epistêmico e moral das situações cotidianas. Com a intercompreensão, Habermas aposta no descentramento do processo de construção do conhecimento, uma vez que na comunicação estão lançados os fundamentos das ações de abertura ao outro, como busca de sentido a ser construído em entendimento coletivo que nos interpela. A performance só é possível porque há um outro, uma diferença, um interlocutor distinto com o qual dialogamos e nos transformamos em comunicação. Essa experiência autoformativa exige o movimento e o jogo performativo do conhecimento como desafio e obra comum para "reconhecer no estranho o que é próprio, familiarizar-se com ele [...], cujo ser é apenas o retorno a si mesmo a partir do ser-outro" (GADAMER, 1999, p. 50).

\section{4 | CONSIDERAÇÕES FINAIS}

Em vista dos argumentos apresentados, podemos constatar que a linguagem interpeladora da expressão traz à fala seu sentido, pois todo o encontro com a arte é um acontecer inconcluso, que nos remete ao diálogo de reconhecimento mútuo. Tudo indica que sem essa abertura mútua de ouvir os outros, tampouco pode existir vínculo humano ou pertença mútua. A racionalidade performativa é simultaneamente imanente, levantada sempre aqui e agora, não podendo ser encontrada fora dos jogos de linguagem, de instruções concretas (que podem ser aceitas ou rejeitadas), e transcendente espaços, tempos e regulações, quando criticamos nossas atividades e organizações. A ideia de desempenho discursivo de pretensões de validez significa que as argumentações do falante (e consequências da ação), só podem ser justificadas em contato com as experiências do outro, ou seja, pela via do reconhecimento intersubjetivo. Dessa forma, tentando responder a questão norteadora da pesquisa, a saber: quais as possibilidades de articular o potencial reflexivo e imaginativo do discurso no mundo de hoje? Podemos constatar que talvez a realização da ação performativa fortaleça a possibilidade de abertura à crítica e à dúvida nos processos de aprendizagem, e não a explicitação como conteúdo do saber, pois são as resistências e limitações dos discursos sobre a realidade, a que estão submetidas nossas soluções de problemas e nossos processos de aprendizado, que se faz notar performativamente.

de engajamento e aperfeiçoamento prático, mas não necessariamente instrumental, dado que as pessoas são capazes de sentir e pensar o que estão fazendo, na busca de excelência na qualidade do trabalho. Todavia, a atividade prática em diferentes momentos da história ocidental foi menosprezada, divorciada de ocupações supostamente mais elevadas (intelectualmente e socialmente) e desvinculada da imaginação, tal qual é concebida ainda hoje a técnica (SENNETT, 2009, p. 29-30). 


\section{A FORMAÇÃO NO DEBATE COMUNICATIVO | Elaine Conte}

Considerando o exposto, a performance gera outros conflitos para Habermas, uma vez que o que é aceito como racional aqui e agora pode se evidenciar como falso, sob condições epistêmicas melhores, diante de um outro público e contra objeções futuras, aparecendo o elemento autocrítico que não pode excluir a possibilidade de desaprender e reprender. Então, como desenvolver um diálogo formativo na atualidade? Percebemos que a virada linguística está de certa forma articulada com a virada virtual, das tecnologias digitais e com as aprendizagens sociais, cuja simples reprodução não consegue reconstruir a realidade. Nesse sentido, o professor tem o compromisso de transcender as opiniões e informações que se trocam ordinariamente nas mídias, como as pretensas evidências compartilhadas que só refletem perspectivas locais, para guiar a ação e fazer um revolucionário diálogo pelo mundo das interpretações, da práxis da arte de compreender e deixar falar o estranho, interrogando sobre as relações despertadas pelo conhecimento no mundo. Certamente, em um processo de entendimento mútuo (virtual ou atual), onde todos somos aprendentes, o saber humano habita na linguagem como espaço aberto de sua continuidade, que obriga o participante a suspender sua relação instituída com o real e interrogar-se no mundo virtual. A ação performativa sempre se renova no presente do saber, como uma potência criadora de sentidos contingentes e de força inovadora, capaz de quebrar as resistências e normas da linguagem e transformá-las no âmbito estético.

Trata-se sempre de aprender pela capacidade de resistência e reconstrução coletiva, reconhecendo a ação comunicativa como dimensão formadora no reconhecimento do outro, que desperta para a pesquisa e o questionamento cotidiano, pois, a racionalidade não significa a posse do saber, mas o modo como os sujeitos modificam e utilizam o saber. Por fim, Habermas (1990a) encaminha um processo formativo que é social, comunicativo e público, apoiado no entrecruzamento complementar do acesso ao mundo, por um lado, pela ação impessoal (de um observador/ ouvinte que assume postura neutra em relação ao mundo), e, por outro, despertada performaticamente (através de práticas de participação social críticas e compartilhadas intersubjetivamente no mundo da vida), pois os modos de agir dependem exclusivamente de nós em relação ao outro e da realidade social complexa no mundo.

O estudo realizado mostra-nos, ainda, que não haveria performance sem a curiosidade que nos move diante do mundo, onde podemos apreender alguma coisa com os outros interlocutores e, quem sabe, conseguiremos escrever uma história melhor do que já foi escrita, sem preconceitos ou imperialismos educativos (ditadura das certezas em modelos de ação). 


\section{A FORMAÇÃO NO DEBATE COMUNICATIVO | Elaine Conte}

\section{Referências}

CAMBI, F. História da pedagogia. São Paulo: UNESP, 1999.

FREIRE, P. Pedagogia da indignação: cartas pedagógicas e outros escritos. São Paulo: Editora UNESP, 2000.

GADAMER, H.-G. La educación es educarse. Tradução Francesc Pereña Blasi. Barcelona: Paidós Ibérica, 2000.

Verdade e método l: traços fundamentais de uma hermenêutica filosófica. 3. ed. Tradução Flávio Paulo Meurer. Petrópolis, RJ: Vozes, 1999.

Verdad y método: fundamentos de una hermenéutica filosófica. 4. ed. Salamanca: Sígueme, 1991. v.1.

GADOTTI, M. Comunicação docente. São Paulo: Loyola, 1985.

HABERMAS, J. Agir comunicativo e razão destranscendentalizada. Tradução Lucia Aragão. Rio de Janeiro: Tempo Brasileiro, 2002.

Comunicação, opinião pública e poder. In: COHN, G. (Org.). Comunicação e indústria cultural: leituras de análise dos meios de comunicação na sociedade contemporânea e das manifestações da opinião pública, propaganda e "cultura de massa" nessa sociedade. São Paulo: Cia. Editora Nacional; Ed. da USP, 1971. (Série, 2, v. 39).

Consciência moral e agir comunicativo. Rio de Janeiro: Tempo Brasileiro, 1989a.

La lógica de las ciências sociales. 3. ed. Madrid : Tecnos, 1996.

Mudança estrutural da esfera pública: investigações quanto a uma categoria da sociedade burguesa. Rio de Janeiro: Tempo Brasileiro, 1984.

O discurso filosófico da modernidade. Lisboa: Dom Quixote, 1990a.

Pensamento pós-metafísico: estudos filosóficos. Tradução de Flávio Beno Siebeneichler. Rio de Janeiro: Tempo Brasileiro, 1990b.

Técnica e ciência como ideologia. Tradução Artur Morão. Lisboa: Dom Quixote, 1994.

Teoria de la acción comunicativa: complementos y estudios previos. Madrid: Cátedra, 1989b.
Teoría de la acción comunicativa I: racionalidad de la acción y racionalización social. Madrid: Taurus, 1987a.

Teoría de la acción comunicativa II: crítica de la razón funcionalista. Madrid: Taurus, 1987b.

Um perfil filosófico-político. In: SADER, E. Vozes do século: entrevistas da New Left Review. São Paulo: Paz e Terra, 1997. p. 125-158.

Verdade e justificação: ensaios filosóficos. Tradução de Milton Camargo Mota. São Paulo: Loyola, 2004.

KANT, I. Sobre a pedagogia. Tradução de Francisco Cock Fontanella. Piracicaba, SP: Ed. UNIMEP, 1996.

MAAR, W. L. Educação crítica, formação cultural e emancipação política na escola de Frankfurt. In: PUCCI, B. (Org.). Teoria crítica e educação: a questão da formação cultural na escola de Frankfurt. Petrópolis, RJ: Vozes; São Carlos, SP: EDUFISCAR, 1994.

MARTINI, R. M. F. Garimpando em Habermas ideias para a reconstrução do currículo. Cadernos de Educação, Pelotas: FaE/UFPel, n. 27, p.115-134, jul./dez. 2006.

Mundo da vida, diálogo e crítica: em busca de atalhos para um encontro entre Habermas e Paulo Freire. In: SILVEIRA, F. T.; GHIGGI, G.; PITANO, S. C. (Org.). Leituras de Paulo Freire: contribuições para o debate pedagógico contemporâneo. Pelotas: Seiva Publicações, 2007. p. 261- 280.

Reencantar a ação educativa, um empreendimento possível? Reflexão e Ação, Santa Cruz do Sul: EDUNISC, v. 13, n. 2, p. 15-21, jul./dez. 2005.

MARTÍN-BARBERO, J. Heredando el futuro: pensar la educación desde la comunicación. Nómadas, Bogotá: Fundación Universidad Central, 1996.

SENNETT, R. O artífice. Tradução de Clóvis Marques. 2. ed. Rio de Janeiro: Record, 2009.

TREVISAN, A. L. Pedagogia das imagens culturais: da formação cultural à formação da opinião pública crítica. ljuí-RS: UNIJUÍ, 2002. 